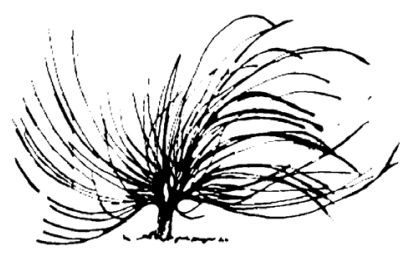

\title{
La didáctica como proceso de enseñar y evaluar el aprendizaje ${ }^{1}$
}

\author{
Alexander Ortiz Ocaña ${ }^{2}$ \\ Universidad del Magdalena \\ Colombia \\ alexanderortiz2009@gmail.com \\ Mileidy Salcedo Barragán ${ }^{3}$ \\ Universidad del Magdalena \\ Colombia \\ milesalba@gmail.com
}

\begin{abstract}
Resumen
El concepto de pedagogía, el tema pedagógico y la pedagogía como ciencia, disciplina, saber o reflexión, han sido estudiados por múltiples autores en todos los continentes. Destacan en este abordaje las tradiciones de Alemania, Francia, Estados Unidos y Latinoamérica. Las concepciones sobre la pedagogía que se han venido configurando a lo largo de la historia de la educación difieren en las diversas regiones y países. Es por ello que un análisis minucioso, detallado y profundo de la configuración
\end{abstract}

\section{(c) $(1) \Theta$}

Recibido: 7 de agosto de 2019. Aprobado: 29 de abril de 2020.

http://dx.doi.org/10.15359/rep.15-2.9

1 Resultado del proyecto Escenarios formativos mediadores de la biopraxis de niños y niñas en contexto de pobreza, financiado por la Universidad del Magdalena. Santa Marta. Colombia. Grupo GIEDU: Grupo de Investigación en Infancia y Educación.

2 Docente de planta de tiempo completo de la Universidad del Magdalena, Santa Marta, Colombia. Doctor en Ciencias de la Educación. Profesor del Doctorado en Ciencias de la Educación RUDECOLOMBIA-Universidad del Magdalena, Colombia. https://orcid. org/0000-0001-5594-9422

3 Doctora en Ciencias de la Educación de la Universidad del Magdalena y RUDECOLOMBIA. Magister en Educación de la Universidad del Magdalena en convenido con el SUE Caribe. Licenciada en Ciencias Físico Matemáticas de la Universidad del Magdalena. Bachiller Normalista. Docente con más de 20 años de experiencia en los distintos niveles de la educación. Actualmente se desempeña como tutora del Programa Todos a Aprender, en el Distrito de Santa Marta, y como Docente Catedrática de la Universidad del Magdalena en el Programa de Licenciatura en Educación Infantil. 
epistémica de la noción de pedagogía requiere tener en cuenta no solo la propia dimensión epistémica de la misma sino además su dimensión geográfica. En este artículo, se reflexiona sobre la didáctica como el proceso de enseñar y evaluar el aprendizaje. Se asume que enseñar significa dejar aprender. Desde esta mirada, el profesor debe entusiasmar, seducir, acoger e inspirar. Se finaliza con una máxima: Dime cómo evalúas y te diré cómo enseñas.

Palabras clave: aprendizaje, didáctica, educación, enseñanza, evaluación, formación, pedagogía.

\begin{abstract}
The concept of pedagogy, the subject of pedagogy and pedagogy as a science, discipline, knowledge, and reflection have been studied by many authors in all continents. This approach includes the traditions of Germany, France, The United States, and Latin America. The conceptions of pedagogy that have been established throughout the history of education differ in the various regions and countries. That is why a thorough, detailed, and profound analysis of the notion of the epistemic configuration of pedagogy requires taking into account not only its own epistemic dimension but also its geographical dimension. In this article, the authors reflects on teaching as the process to teach and assess learning. It is assumed that teaching means allowing learning. From this point of view, a teacher must excite, seduce, welcome, and inspire. This article ends with a maxim: tell me how you evaluate, and I will tell you how to teach.
\end{abstract}

Keywords: education, training, pedagogy, didactics, teaching, learning, assessment

\title{
Introducción
}

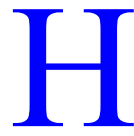

ernández (1969) señala que el término aprendizaje proviene del latín aprehendere; de ad, a, y prehendere, que significa agarrar o percibir. En términos generales, se le puede considerar como la búsqueda constante de una plena realización (Ferrini, 2001). En la actualidad, es aceptado que la explicación oral del profesor es apenas el comienzo de la estimulación del proceso de aprendizaje del estudiante, pero no es el método ideal para lograrlo. La integración de lo aprendido 
por el estudiante y su aplicación a su vida cotidiana configuran el verdadero aprendizaje (Trejo, 2012).

Aprendizaje es un vocablo polisémico y complejo. A veces se asocia a instrucción, asimilación, amaestramiento e incluso a enseñanza. El aprendizaje como proceso de los seres vivos es muy complejo. En ocasiones se distingue el aprendizaje animal y el humano y se contrapone a la enseñanza. Para Flórez (2005), el aprendizaje es una palabra que se refiere a "aquellos procesos conscientes que desembocan en modificaciones mentales duraderas en el individuo. No se opone a enseñanza sino al contrario, una enseñanza de buena calidad asegura el aprendizaje" (p. 348). Este autor considera que el concepto de aprendizaje y desarrollo individual no es el mismo en cada modelo pedagógico, sino que en cada uno de ellos varían. Por ello, es importante que en la escuela los profesores hagan el debate y asuman una concepción sobre el aprendizaje, en la cual se va a sustentar el modelo pedagógico que ellos configuren en la organización educativa, al analizar las diversas teorías educativas que han proliferado en el devenir histórico de la humanidad.

Moreno (1993) distingue dos tipos de aprendizaje, uno al que le llama aprendizaje en sentido estricto y otro aprendizaje en sentido amplio. El primero está relacionado con la asimilación de información específica y datos concretos, es lo que conocemos comúnmente como aprendizaje, es el aprendizaje propiamente dicho. Sin embargo, el aprendizaje en sentido amplio se asocia más al desarrollo humano. Se ha escrito mucho sobre la relación entre aprendizaje y desarrollo, y los debates que han llegado hasta nuestros días están marcados por la impronta constructivista liderada por Piaget $(1945,1954)$, así como por la psicología de Vygotsky $(1979,1981)$. Los constructivistas asumen un modelo en el que el desarrollo es la base para el aprendizaje y lo determina, asignándole al desarrollo un papel preponderante en la relación. Los seguidores de la postura vygotskyana asumen lo contrario: el aprendizaje precede, conduce y genera el desarrollo. Pensamos que es necesario plantear criterios más dialécticos por cuanto el aprendizaje de un ser humano depende de su desarrollo alcanzado, es este el que predetermina lo que puede ser aprendido, pero a su vez, la implicación y el nivel aprendizaje garantiza un mejor desarrollo. En definitiva, la comprensión de la experiencia depende de las estructuras y esquemas del sujeto, y estas se modifican de acuerdo con la experiencia. Los mismos mecanismos equilibrantes rigen ambos procesos (Castorina et al. 1996). Ahora bien, es preciso señalar 
que, a lo largo del desarrollo de la historia de la educación, el discurso se ha concentrado más en la enseñanza que en el aprendizaje. Se habla más del rol del profesor y muy poco del rol de los estudiantes. Cuando se hace referencia al aprendizaje de los estudiantes, enseguida el discurso toma un giro hacia la enseñanza del profesor, y se investiga más el proceso de enseñar y muy poco el proceso de aprender. Incluso se habla muy poco de la calidad del aprendizaje, se habla más de la calidad de la enseñanza (Santos, 2012), cuyo resultado se evidencia en el rendimiento académico de los estudiantes. Incluso se hacen pruebas internacionales para evaluar la calidad de la educación que ofrecen los distintos países.

Finlandia, Japón y Corea del Sur obtienen los primeros lugares en las pruebas de la OCDE. Pero lo más importante no es limitarnos a mirar esos resultados y auto-criticarnos o escuchar las críticas pasivas de los gobiernos, quienes siempre transfieren a los profesores la responsabilidad de los bajos resultados de los estudiantes. Sin embargo, si analizamos las características del sistema educativo de estos países, veremos que está muy lejos de los países latinoamericanos, tan lejos que no se admiten comparaciones. Por ejemplo, en Finlandia, la educación escolarizada se desarrolla desde los 7 hasta los 16 años, las escuelas permanecen abiertas todo el día, con el fin de desarrollar actividades conjuntas con la comunidad. En estas actividades, se integran los estudiantes, padres de familia y profesores. Desarrollan diversas actividades académicas, artísticas, culturales, científicas, deportivas y recreativas. Los estudiantes no tienes tareas extraescolares ni compromisos académicos para sus casas, pero la atención es personalizada, en función del diagnóstico de necesidades académicas o de los resultados de su aprendizaje, que no se evalúa de manera cuantitativa sino cualitativa y descriptiva, una evaluación que orienta su proceso de aprendizaje. No obstante, este sistema de evaluación de la calidad de la educación basado en exámenes estandarizados es un reflejo del modelo neoliberal que propende por el crecimiento económico, lo que soslaya el desarrollo humano y la configuración holística de la personalidad de los estudiantes. Es necesario un aprendizaje que estimule "la participación activa de los alumnos mediante la investigación, las preguntas y la indagación" (Nussbaum, 2013, p. 39), que retome las propuestas del movimiento de la escuela nueva o activa, el cual tiene su germen en las ideas de Rousseau (2011), esbozadas en el siglo XVIII, que se consolidan en las propuestas de Dewey $(1926,1964,1989,1997$, 2003, 2004) en el siglo XX. 
Las teorías del aprendizaje activo y participativo se fueron configurando a partir de las propuestas de notables pedagogos como Johann Pestalozzi (Suiza), Friedrich Fróbel (Alemania), María Montessori (Italia), Celestín Freinet (Francia) y Bronson Alcott (Estados Unidos), entre otros no menos importantes, quienes consideraban que el aprendizaje no puede relacionarse con la asimilación y absorción pasiva de datos e informaciones, de manera acrítica, mecánica y dogmática, sino que es necesario plantear retos al intelecto del estudiante para que este se convierta en una persona activa, competente y competitiva, con un pensamiento crítico, reflexivo y creativo que le permita sobrevivir en un mundo cada vez más complejo, dinámico, cambiante y problemático. Ahora bien, si bien es cierto que este movimiento se configura a partir del siglo XVIII, la génesis del mismo la podemos encontrar en la actividad de Sócrates, quien con su "conócete a ti mismo" y "sólo sé que nada sé", sentó las bases para un aprendizaje auténtico, activo, productivo, participativo y desarrollador.

Durante el siglo XX, se produjeron importantes avances en la comprensión de la naturaleza, características y variables del aprendizaje. Rogers (1978) considera que el ser humano tiene una capacidad innata para aprender, de ahí que su aprendizaje emerge de manera oportuna si dicha capacidad no se obstaculiza. Podemos considerar, además, altamente significativos, los aportes de Piaget (1945, 1954), Vygotsky $(1979,1981)$, Ausubel $(1958,1963,1980)$ y Bruner $(2000,2012)$. De una u otra manera, todos estos autores valoran el aprendizaje como un proceso social que debería potenciarse mediante grupos colaborativos en los cuales interactúen los pares en escenarios naturales.

En este artículo, reflexionamos sobre el rol del profesor y la concepción de la enseñanza (que debe estar sustentada en la concepción del aprendizaje y en el rol del estudiante). Se reflexiona sobre la didáctica como el proceso de enseñar y evaluar el aprendizaje. Se asume que enseñar significa dejar aprender. Desde esta mirada, el profesor debe entusiasmar, seducir, acoger e inspirar. Se finaliza con una máxima: Dime cómo evalúas y te diré cómo enseñas.

\section{Enseñar significa dejar aprender}

Antes del siglo XVII, la enseñanza se desarrollaba mediante prácticas dispersas. Fue en el año 1632 con la publicación de la obra Didáctica Magna, de Juan Amos Comenio, que comienza a configurarse un discurso sistematizado en torno a ella. A partir de esta fecha la enseñanza comienza 
a ser considerada como la actividad que caracteriza el rol y modo de actuación del profesor, que implica unos propósitos, unos contenidos, unas técnicas y procedimientos y un lugar específico: la escuela.

Comenio (2012) consideraba que no es posible enseñar a cada estudiante de manera particular porque el talentoso aprende más y más rápido, y otros estudiantes tienen un aprendizaje más lento, sin embargo, era consciente de que cada niño podría ser formado, y por eso quería enseñar a todos, y mejor de lo que le habían enseñado a él. Consideraba la enseñanza como una actividad en la que es necesario "ir de lo conocido a lo desconocido, de lo simple, a lo compuesto, de lo próximo a lo lejano, de lo regular a lo irregular, de lo concreto a lo abstracto" (p. 178), de esta manera lleva el procedimiento del conocimiento científico a la actividad escolar, a la enseñanza, concepto que en su obra cobra un alto significado por el nivel de coherencia, sistematización, armonía y unidad que logra. "Gracias al concepto de enseñanza pudo la Escuela Nueva reformular el concepto de aprendizaje. Gracias al concepto de enseñanza pudo la sociología de la educación pensar la escuela" (Zuluaga, 2003, p. 64).

Por otro lado, según Herbart $(1806,1935)$, la enseñanza transita por cuatro momentos: la claridad, la asociación, la sistematización y el método, es decir, la enseñanza debe mostrar, asociar, enseñar y filosofar. Esta terminología fue modificándose, desarrollándose, sistematizándose hasta distinguir la intuición, la comparación, la abstracción, y finalmente la aplicación. Herbart (1806), además propone tres modos, tres métodos para ser utilizados en cada uno de los cuatro momentos de la enseñanza: descriptivo, analítico y sintético.

Como se aprecia, Herbart (1806) mecanizó la actividad de enseñanza, al igual que ya lo había hecho Pestalozzi (2011). Ambos reglamentaron, el orden de las actividades que debían desarrollar los niños, al seguir esquemas inflexibles, bajo la autoridad del padre o el profesor. Las reglamentaciones para la enseñanza impedían la creatividad y originalidad del profesor, quien limitaba la libertad y espontaneidad de los estudiantes.

Según Hernández (1969), la palabra enseñanza proviene del vocablo latino insignare, que significa señalar, y consiste en el sistema o método de dar una instrucción. También es definida como la acción que ejerce el profesor para trasmitir un determinado contenido a los estudiantes (Manuel y Saavedra, 2001). Esta es una concepción positivista 
y tradicional de la enseñanza, concebida solo como transmisión, se asume como un acto unidireccional y no tiene en cuenta la acción del estudiante, sin embargo, es necesario precisar que solo puede hablarse de la existencia de la enseñanza en la medida en que se obtenga una reacción de aprendizaje (Contreras, 1999). Desde esta mirada, enseñar es orientar el proceso de aprendizaje de los estudiantes, ya Titone (1979) había afirmado que "la enseñanza auténtica consiste en proyectar, orientar y controlar experiencias concretas de trabajo reflexivo de los alumnos, sobre los datos de la materia escolar o de la vida cultural de la humanidad" (p. 37).

Por otro lado, Zuluaga, Echeverri, Martínez, Restrepo y Quiceno (2003) consideran que enseñar es "tratar contenidos de las ciencias en su especificidad con base en técnicas y medios para aprender en una cultura dada con fines sociales de formación del hombre" (p. 40). Aquí se concibe la enseñanza como una actividad encaminada al aprendizaje, una actividad específica y praxeológica que reproduce y transmite cultura desde la propia cultura dominante.

Martínez (2003) propone reconceptualizar la enseñanza de manera que no se asocie solo al componente instrumental. La asume para pensar como ejercicio artístico, y no solo una actividad procedimental encaminada al logro del aprendizaje de conocimientos. Sugiere no ver la enseñanza solo como una actividad empírica y pragmática, encaminada al control, al rendimiento, a la eficiencia, sino como la posibilidad de relacionarse con el pensamiento como un evento complejo del ser humano.

Freud (2012) afirmaba con frecuencia que existen tres funciones imposibles de definir: educar, gobernar y psicoanalizar, porque más que funciones o profesiones son actividades humanas, presentes en todos los momentos de nuestra vida. Sin embargo, el profesor se convierte en un funcionario debido a la dimensión funcional de la enseñanza, y se convierte en un experto debido a su dimensión profesional. La enseñanza debe recuperar su dimensión política y no ser considerada solamente una función, una profesión, una especialización (Morín, Ciurana y Motta, 2003), debe estar encaminada a formar para la vida, para lo cual no basta solamente con la competencia didáctica y los saberes científicos, sino que se necesita además la dimensión artística.

"El amor origina la profesión pedagógica, la verdadera misión del educador" (Morín, 2007, p. 79). Platón decía que para enseñar hacía falta Eros, que no es solo el deseo de transmitir conocimientos y 
sentir el placer de comunicar, sino además el amor a lo que se piensa, se dice y se hace.

"Enseñar es crear. Es invención, ingenio, innovación, gracia, tenacidad" (Marina, 2014, p. 133). Desde esta mirada, la enseñanza no implicaría procedimientos específicos ni pasos formales para el aprender, solo mostraría la posibilidad de un pensar dialógico para provocar, incitar y gatillar, en términos de Maturana (1999). "No mostrar caminos ya recorridos, pavimentados que llevan hacía lo esperado; no una enseñanza programática hacia unos fines delimitados sino más bien una enseñanza diagramática como incitación a lo impensado" (Martínez, 2003, p. 210).

Ball (1988) critica que la enseñanza está siendo permeada por el mercado y su lógica de producción y competición, "las tecnologías del control reemplazan la disputa ideológica abierta... En este discurso, el currículum se convierte en un sistema de reparto y los profesores, en sus técnicos u operarios" (p. 292). En este sentido, la escuela se convierte en una institución reproductiva, que solo transcribe, imita y representa la cultura dominante de la sociedad, y en muchas ocasiones de manera acrítica y dogmática, sin cuestionar actividades y procesos que son inaceptables desde una mirada ética (Santos, 2012).

"Pensar la enseñanza como un acontecimiento complejo de saber y de poder, es buscar una cultura de la enseñanza y no sólo enseñar la cultura" (Martínez, 2003, p. 211), como se ha hecho hasta nuestros días. Es cambiar el modelo reproductivo por el modelo emancipador. No se trata de adoctrinar a nuestros estudiantes al transmitir el conocimiento absoluto que promueve el paradigma dominante, sino darles la posibilidad de pensar, reflexionar, para que puedan actuar y decidir su destino, sin necesidad de que tengan que asumir los postulados del sistema que ostenta el poder.

"La reforma de la enseñanza debe conducir a la reforma del pensamiento y la reforma del pensamiento debe conducir a la reforma de la enseñanza" (Morín, 2008, p. 21). Mejorar la calidad de la enseñanza no es una cuestión de métodos didácticos sino de configuración de un nuevo paradigma cognitivo, nuevas formas de pensar, cambiar nuestra mentalidad relacionada con las formas tradicionales de enseñar y no pensar que para tener éxito en nuestra actividad de enseñanza debemos transmitir a los estudiantes nuestros conocimientos, sino activar su 
pensamiento para que configuren por sí mismos sus propios saberes. El método es pensar, no solo escuchar lo que diga el profesor.

"La enseñanza es el espacio que posibilita el pensamiento y el acontecimiento de saber que define múltiples relaciones posibles con el conocimiento, las ciencias, el lenguaje, el aprender, con una ética" (Zuluaga, Echeverri, Martínez, Restrepo y Quiceno, 2003, p. 40). La enseñanza debe ser crítica, dialéctica y dialógica. Crítica en el sentido de que el estudiante no debe asimilar y aceptar los postulados de su profesor, sin reflexionar sobre lo que este le está planteando, y el profesor no debe transmitir al estudiante de manera dogmática los contenidos que aparecen expuestos en los libros. Dialéctica desde la definición que ofrece Platón como el arte de confrontar y de organizar los conceptos. Dialógica porque el profesor debe establecer una conversación armónica con sus estudiantes, en la que se entrelazan el lenguajear y el emocionar, que suscitan el interés, motivación, curiosidad y deseo del estudiante.

La enseñanza no es más que una actividad amena en la que los sujetos de la educación conversan de manera animada. De ahí que "sólo podemos enseñar basándonos en el sujeto, en sus adquisiciones anteriores, en las estrategias que le resultan familiares" (Meirieu, 2009, p. 158), al tratar de relacionar lo nuevo que se aprende con los conocimientos anteriores, de esta manera "la primera misión de la enseñanza es aprender a religar, más aún ahora que se aprende demasiado a separar. Al mismo tiempo, es necesario aprender a problematizar" (Morín, 2007, p. 77). Enseñar es elaborar situaciones de aprendizaje con el fin de provocar la curiosidad y el asombro del estudiante. Es estimular el pensamiento del sujeto que aprende con el fin de que este desarrolle una elaboración activa y configure nuevos procesos cognitivos en su estructura intelectual, y "es el momento de materialización y de transformación de los conocimientos en saberes, en virtud de la intermediación de la cultura" (Zuluaga, Echeverri, Martínez, Restrepo y Quiceno, 2003, p. 40).

La enseñanza, desde la mirada de Simmel (2008), debe suscitar el interés por un contenido determinado, por cuanto este es un momento que tiene un potencial educativo extraordinario, es uno de los valores funcionales que deben ser configurados con el acto de aprender dicho contenido, que se convierte en un lazo, un viaducto entre profesor y estudiante, un puente por el que transitan amor y confianza del estudiante al profesor. "Enseñe lo que enseñe y donde quiera que lo enseñe, un profesor siempre enseña algo a alguien" (Meirieu, 2011, p. 56), sin 
embargo, esto no significa que enseñar es trasladar los conocimientos de la mente del profesor a la mente de los estudiantes, y mucho menos solo ofrecerles información. La enseñanza no debe verse como una actividad de transmisión de conocimientos. De Zubiría (2008) entiende por enseñar el proceso específicamente humano de transferirles instrumentos y operaciones mentales a los estudiantes, para que dominen las herramientas de su cultura. Enseñar no es transmitir, es orientar el aprendizaje de los estudiantes, guiarlos, organizar situaciones problémicas de aprendizaje que encierren una contradicción, una tensión, para crear conflictos cognitivos y que así se estimule el pensamiento del estudiante. Sin conflictos cognitivos no se aprende, y en este sentido "el maestro no «ayuda» al discípulo de ninguna manera, puesto que ayudar sería en realidad entorpecer. Por el contrario, sale a ponerle obstáculos y barreras en el camino del estudiante" (Watts, 2012, p. 316).

Ayudar en el proceso de enseñanza consiste en poner obstáculos cognitivos para que el estudiante aprenda. Mientras más barreras intelectuales coloque el profesor más y mejor aprende el estudiante. Las contradicciones generan el desarrollo humano, las tensiones intelectuales generan aprendizaje auténtico, productivo y desarrollador. De esta manera, el estudiante podrá comprender lo que aprende y podrá comprender a su profesor, a la vez que este lo comprende.

Toda enseñanza es autoritaria, adoctrinante y coactiva, todo acto de enseñanza provoca tensiones, contradicciones y luchas entre dos voluntades, la que quiere enseñar (profesor) y la que no quiere que le enseñen (estudiante). A ningún niño le gusta ir a la escuela, no le gusta que le enseñen, porque la actividad que regula su conducta en esta etapa etaria no es el estudio, sino el juego. A los niños les gusta jugar, mas no que les enseñen. Sí les gusta aprender, pero jugando, no de la forma en que se les enseña actualmente.

La enseñanza es una relación entre seres humanos, es una actividad interpersonal en la que ambos sujetos, el profesor y los estudiantes, tienen el propósito de comprenderse, "y en este proceso de búsqueda pueden observarse las cualidades del docente como artista escénico" (Sarason, 2002, p. 194). Como se aprecia, enseñar es más difícil que aprender.

¿Por qué es más difícil enseñar que aprender?, se pregunta Heidegger (1978). "El enseñar es más difícil que aprender porque enseñar significa: dejar aprender. Más aún: el verdadero maestro no deja aprender nada más que el aprender" (p. 20). Enseñar es más difícil que 
aprender no por la cantidad de conocimientos que supuestamente debe acumular un profesor para transmitirlos a sus estudiantes. Por eso, en ocasiones algunos padres de familia se quejan de la escuela cuando les preguntan a sus hijos qué clases recibió y qué le enseñaron, y este le contesta que solo jugaron. Los padres de familia piensan erróneamente que aprender es depositar un caudal de conocimientos. Enseñar no es transmitir conocimientos sino dejar aprender.

La enseñanza es una actividad humana y profesional que exige un alto grado de desarrollo de la competencia científica y didáctica, pero sobre todo mucha originalidad, creatividad y amor. No hay enseñanza sin aprendizaje, siempre que el profesor enseña, el estudiante aprende. No existe el aprendizaje cero o nulo. Pero cuando decimos que el enseñar no existe sin el aprender, nos referimos además a que el profesor, al enseñar, aprende; y el estudiante, al aprender, enseña. El enseñar y el aprender están interconectados, son dos caras de una misma moneda, dos lados de una misma rueda. La enseñanza y el aprendizaje son dos procesos que se interpenetran entre sí. La buena enseñanza es aquella que genera aprendizaje, aquella que se diseña, concibe y ejecuta en función del aprendizaje. "El valor más importante de la enseñanza está en el aprendizaje, al punto de ser su finalidad, su verdadero sentido, el más profundo y solidario" (Zambrano, 2011, p. 76). La calidad de la enseñanza no debe valorarse por lo que hace el profesor sino por lo que sus acciones provocan en los estudiantes. El aprendizaje es la finalidad del proceso educativo, y la enseñanza es el medio para alcanzar ese fin. El aprendizaje debe tener la preponderancia en su relación con la enseñanza. Esta es una concepción muy diferente a la mirada limitada de Flórez (2005), quien concibe la enseñanza como el "proceso intencional y planeado para facilitar que determinados individuos se apropien creativamente de alguna porción de saber con miras a elevar su formación" (p. 350).

Para que la actividad de enseñanza cumpla su función, es necesario que "el acto de aprender sea precedido por, o concomitante de, el acto de aprehender el contenido o el objeto cognoscible, con el que el educando también se hace productor del conocimiento que le fue enseñado" (Freire, 2012, p. 143). Enseñar no es transferir conocimiento sino crear un ambiente de aprendizaje para que el estudiante tenga las posibilidades de su configuración. Enseñanza y aprendizaje forman un par dialéctico, son procesos dialógicos y complementarios. Enseñar no existe sin aprender y viceversa. El estudiante, cuando aprende, enseña 
en su proceso de aprendizaje, y el profesor, al enseñar, aprende en su proceso de enseñanza.

El aprendizaje surgió primero que la enseñanza en la historia de la humanidad. Fue aprendiendo socialmente que los seres humanos se percataron que era posible enseñar. Aprender precedió a enseñar y la enseñanza se diluía en la experiencia realmente fundadora de aprender (Freire, 2014). La enseñanza no es válida si no logra que el estudiante aprenda al recrear y al reconfigurar lo enseñado. Un profesor enseña cuando fomenta el aprendizaje de sus estudiantes, cuando estimula y facilita que estos se motiven, comprometan y participen de manera activa en ese proceso de configuración cognitiva y axiológica, al cuestionar sus propias formas de pensar y al crear nuevos paradigmas mentales, nuevas formas de pensar, aprender, reaprender y reconfigurar el mundo en que vive. Como ya ha dicho Morín (2011), "los analfabetos del siglo XXI no serán los que no sepan leer ni escribir, sino los que no puedan aprender, desaprender y reaprender" (p. 144).

En nuestra forma de pensar tradicional está impregnado un modelo anticuado y erróneo de enseñanza, que considera la explicación como la base de esta. Es muy difícil imaginarse a alguien que enseña a otra persona sin ofrecerle una explicación, ilustración o argumentación. Es muy difícil enseñarle a alguien sin hablar. Los profesores pensamos que para enseñar debemos hablar y transmitirles a nuestros estudiantes lo que ya nosotros sabemos. Finkel (2008) rompe con todos estos esquemas y dogmas mentales y nos exhorta a configurar una nueva comprensión de lo que podría significar crear un ambiente de enseñanza sin hablar, un creativo entorno de aprendizaje que estimula a los estudiantes a tener la dirección y control de su propio aprendizaje. Finkel (2008) nos exhorta a enseñar con la boca cerrada.

Esta concepción didáctica podemos encontrarla en Dewey (2004), quien consideraba que la enseñanza no está relacionada con el acto de narrar sino con un proceso activo de construcción. Sin embargo, el reconocimiento de este principio didáctico ha contribuido a enriquecer la teoría, pero se viola constantemente en la práctica pedagógica de los profesores, quizá porque este enfoque de enseñanza es narrado y explicado.

Es asombroso conocer que hace casi 100 años se reconoce este principio didáctico y, sin embargo, se ignora en la praxis educativa. Estas ideas esbozadas por John Dewey en el lejano 1916 no se han tenido en cuenta para fomentar un aprendizaje auténtico, profundo y desarrollador. 
Ken Bain, en su libro Lo que hacen los mejores profesores universitarios, señala que los profesores con más éxito esperan de sus estudiantes los más altos niveles de desarrollo, no consideran la enseñanza solo como un acto de transmitir conocimientos fabricados y brindar respuestas correctas a los estudiantes. Para Bain (2007) la enseñanza consiste en diseñar un entorno de aprendizaje que implique atraer a los estudiantes, lo cual exige, previo al acto de enseñanza, formular las siguientes preguntas:

¿Qué deberían ser capaces de hacer intelectual, física o emocionalmente mis alumnos como resultado de su aprendizaje?, ¿Cómo puedo ayudarlos y animarlos de la mejor manera para que desarrollen esas habilidades y los hábitos mentales y emocionales para utilizarlas?, ¿Cómo podemos mis estudiantes y yo entender mejor la naturaleza, la calidad y el progreso de su aprendizaje?, y ¿Cómo puedo evaluar mis intentos de fomentar ese aprendizaje? (p. 62)

Sin lugar a duda, los profesores que obtienen mejores resultados en el proceso de enseñar son aquellos que conciben mejores ambientes de aprendizaje para sus estudiantes, al asignarle a la enseñanza una función de fomento del aprendizaje y no considerarla como un acto de transmisión, se preocupan por el desarrollo integral de sus estudiantes y tratan de comprender cómo llevar a cabo el acto de enseñar, de tal manera que estimule el deseo de aprender.

De las prácticas pedagógicas de los profesores que estudió Bain (2007), emergen siete principios didácticos que este autor describe en su libro: atraer a los estudiantes al razonamiento disciplinar, buscar y lograr el compromiso de los estudiantes, configurar un entorno para el aprendizaje crítico natural, conseguir la atención y concentración de los estudiantes y no perderla, crear experiencias diversas de aprendizaje, enseñar a los estudiantes a aprender fuera de la clase, pensar y valorar a los estudiantes en lugar de concentrarse en la disciplina.

Una buena enseñanza capta la atención de los estudiantes, inspira, motiva, potencia el pensamiento y la comprensión, y los incita a preguntar. La buena enseñanza hace hablar a los estudiantes, los hace pensar, reflexionar y los incita a participar en un debate o intercambio de ideas y estimula la imaginación. La enseñanza de excelencia no se preocupa por 
la actuación del profesor sino por la esencia, la naturaleza y los procesos del aprendizaje de los estudiantes. Enseñar desde esta concepción exige crear condiciones para que nuestros estudiantes aprovechen al máximo su potencial de aprendizaje. "A menudo, la mejor enseñanza es tanto una creación intelectual como un arte escénica" (Bain, 2007, p. 195). Sin embargo, quien enseña sin emancipar atonta (Rancière, 2010), y el profesor emancipador no debe preocuparse por lo que el estudiante debe aprender, este aprenderá lo que desee: mucho, poco o nada. Así, enseñar consiste en dejar aprender, dejar ser, permitir. El profesor emancipador se preocupa por las actividades que realizan niños y niñas en las horas del recreo o en los diez primeros minutos de clase, sin entorpecer su actividad lúdica espontánea, que tiene un amplio carácter formativo. Es por ello que Cela y Palou (2011) recomiendan que "dejéis tiempos y espacios que las criaturas puedan regular, puedan hacer suyos. Observadlos de lejos y mirad cómo juegan durante esos momentos" (p. 117). Eso también es enseñar, dejar jugar y divertirse.

Como se aprecia, a lo largo de la historia de la educación podemos encontrar propuestas concretas de enseñanza que sirven de orientación a los profesores para desarrollar de una manera adecuada sus prácticas pedagógicas. Aquí pudiéramos mencionar los aportes de Piaget $(1945,1954)$ en lo relacionado con los procesos de asimilación y acomodación, el concepto de andamiaje aportado por Bruner (2000), la propuesta de organizador avanzado de Ausubel (1980) y la noción de zona de desarrollo próximo esbozada por Vygotsky $(1979,1981)$. Todas estas propuestas se han aplicado en la práctica escolar, pero de una manera aislada, y no se ha logrado desplegar, a partir de ellas, un modelo didáctico armónico y coherente. "Estos autores tampoco lograron configurar un enfoque didáctico que les permitiera orientar el trabajo docente" (Díaz-Barriga, 2012, p. 72).

Es importante leer a todos estos autores clásicos para la mejora de nuestro desempeño pedagógico, sin embargo, la mayoría de los profesores, en su biopraxis didáctica, utilizan sus propias ideas. Es por ello, que es importante la formación permanente del profesorado como premisa previa para el desarrollo del currículo. Cuando los profesores plasman sus propias ideas en el modelo pedagógico de la organización educativa, aumenta su motivación, compromiso, responsabilidad y sentido de pertenencia a ella. Además, sus ideas expuestas en el macrocurrículo de la institución se convierten en mecanismos generadores de 
estrategias didácticas novedosas y originales para ser utilizadas en su práctica pedagógica. No obstante, no podemos ignorar los aportes de diversos pedagogos que han configurado disímiles teorías a lo largo de la historia de la educación, las cuales despliegan el rol del profesor en correspondencia con la concepción de enseñanza que han configurado.

\section{El profesor debe entusiasmar, seducir, acoger e inspirar}

Si reflexionamos sobre el quehacer pedagógico de los profesores y los diversos modos de actuación y conductas que este puede asumir, al seguir la teoría de los intereses cognoscitivos (Habermas, 1982), tendríamos que llegar a la conclusión que en su desempeño el profesor podría mostrar al menos una de tres posturas pedagógicas: autoritaria (tradicional), comprensiva o crítica, según los intereses que guíen su práctica pedagógica: técnico, práctico o emancipatorio, de manera respectiva. El interés técnico implica una práctica pedagógica autoritaria, impositiva, en la que el estudiante es considerado un objeto y por tanto debe asumir un papel de receptor pasivo en su proceso de aprendizaje para que el profesor le transmita los conocimientos. En cambio, en la práctica pedagógica orientada por intereses prácticos predomina la comprensión de los intereses y necesidades de los estudiantes, el profesor aplica la deliberación en sus clases y le atribuye significado al proceso educativo, que es la base para la transformación de la conciencia, intencionalidad de una práctica pedagógica crítica orientada por intereses emancipatorios.

Esta concepción epistemológica de los intereses cognoscitivos es aplicable no solo a los métodos didácticos que utiliza el profesor sino además a los contenidos curriculares e incluso a la evaluación educativa. Por ejemplo, si el profesor solo enseña los contenidos tal como están determinados en el programa del área que desarrolla, entonces su interés sería técnico. Por el contrario, si reflexiona sobre dichos contenidos, los cambia, modifica o complementa, entonces su interés es práctico. Pero si el profesor orienta la reflexión de los estudiantes para que estos propongan otros contenidos y valoren sus fines, sentido y significado para modificaciones más profundas, entonces el interés del profesor sería emancipatorio.

Un profesor tradicionalista, guiado por intereses técnicos, desarrollaría una práctica evaluativa en la que el éxito se define por los resultados alcanzados en un examen según unos objetivos previstos 
previamente y la evaluación no se valora como un proceso sino como un resultado, separada de los procesos de enseñanza y aprendizaje. En cambio, un profesor con intereses prácticos desarrollaría una evaluación integrada al proceso de enseñar y aprender, en la que ambos sujetos del proceso educativo, estudiantes y profesor, puedan emitir juicios de valor acerca de su desempeño y de manera intersubjetiva se configure el proceso evaluativo. Asimismo, un profesor orientado por intereses emancipatorios aplica una evaluación crítica en la que se hace una valoración holística del proceso educativo y se cuestiona no solo el contenido de lo aprendido sino además las formas interactivas en las que participan tanto el profesor como los estudiantes.

Como se aprecia, el análisis del rol del profesor desde la mirada de los intereses cognoscitivos definidos por Habermas (1982) tiene la potencialidad que permite tener una aproximación a los rasgos caracterológicos de su práctica pedagógica. Esto no quiere decir que los intereses se manifiesten de manera aislada en su práctica pedagógica y que este manifieste solo un interés cognoscitivo, sin evidenciarse los otros dos. En ocasiones, los intereses se entrelazan y en la práctica pedagógica del profesor pueden evidenciarse los tres tipos de interés, aunque siempre predomina uno de ellos. Por ejemplo, los profesores de la educación infantil han sido formados bajo la perspectiva del interés técnico, sin embargo, se le exige la aplicación de una didáctica constructivista (práctica pedagógica sustentada en un interés práctico), y además contribuir a la formación de estudiantes críticos, lo cual implica intereses emancipatorios (Pasek, 2006). Sin lugar a dudas, una organización es lo que sean los seres humanos que se desempeñan en ella. La escuela es lo que sean sus profesores. Una institución educativa de calidad es aquella que tiene profesores de calidad. El profesor del siglo XXI, sin necesidad de que sea un psicólogo, un neurocientífico, o un sociólogo, debe tener algunos conocimientos mínimos sobre el funcionamiento de la mente, el cerebro y la sociedad. El ser humano es un ser bio-psico-social, el aprendizaje humano depende de la interacción mente-cerebro-sociedad. El profesor del tercer milenio debe dominar el contenido de la asignatura que desarrolla, pero más que ese dominio conceptual, debe conocer a sus estudiantes, admirarlos, amarlos, ser paciente con ellos, respetar sus ritmos, estilos y estrategias de aprendizaje, no acelerar su proceso, no querer obtener rápidamente un resultado final. Tanto el proceso como el resultado son importantes, pero el profesor debe interesarse más por el 
proceso que por el resultado. Su labor no es sencilla como otros profesionales piensan, es una labor muy compleja y por eso Herbart (1806) alertaba que "el educador no debe tener exigencias que le alejen de los fines de la educación" (p. 58), para que pueda superarse, estudiar, leer, y diseñar innovaciones educativas y métodos de enseñanza cada vez más creativos, originales y auténticos. El profesor debe conocer de manera suficiente a sus estudiantes, sus necesidades, experiencias, conocimientos y destrezas, no para cuestionarlos y criticarlos sino para orientarlos.

Es lacónica pero muy reveladora y demostrativa la expresión que Santos (2012) le escuchó en cierta ocasión a Thomas S. Popkewitz: "Los profesores suelen ser personas encantadoras. Lo que pasa es que trabajan en lugares horribles" (p. 22). Esto le permite afirmar a Santos que "en un contexto organizativo educativamente pobre es más difícil ser un buen profesional de la enseñanza" (p. 101), con lo cual discrepamos porque, precisamente en contextos adversos es donde el profesor debe mostrar su inteligencia, sus competencias pedagógicas, curriculares y didácticas, su alta capacidad de resiliencia y transformación del medio, su compromiso con la educación y responsabilidad con el cambio y el mejoramiento futuro. El contexto hace al maestro, pero un profesor comprometido, motivado, sensible y consciente de su encargo social, será capaz de sobreponerse a la desorganización del sistema educativo donde se desempeña y, con su pensamiento crítico, reflexivo y creativo, será capaz de provocar cambios en dicho sistema. "Los profesores son agentes imprescindibles para mantener o modificar las pautas básicas del modelo tradicional de enseñanza en la escuela obligatoria e ignorar o abordar los problemas que dicho modelo genera" (Porlán y Rivero, 1998, p. 9).

"Cuando decimos que alguien es profesor, queremos decir que tiene algo que profesar" (Sarason, 2002, p. 37). El profesor profesa su opinión, sus criterios, sus juicios y valoraciones, sus puntos de vista, su forma de organizar la enseñanza, sin embargo, para lograr la potenciación del desarrollo de sus estudiantes, debe tratar de hablar menos que este. Dar clase con la boca cerrada es la frase que utiliza Finkel (2008) para sugerir que el profesor tiene múltiples alternativas de cumplir su rol y que la única forma no es la que tradicionalmente conocemos por nuestra imagen cultural del buen profesor, que habla, explica, narra y argumenta. Dar clase con la boca cerrada es permitir que sean los estudiantes quienes piensen, sientan, hablen y argumenten sus posturas intelectuales. De ahí que el principal rol del profesor de excelencia es 
no comenzar la actividad de enseñanza pensando y hablando del contenido de la asignatura, sino ubicar al estudiante en el centro de dicho proceso. La clase debe empezar con el estudiante, no con el contenido.

El profesor no es un simple instructor, no es un dictador de clases ni un impartidor de asignaturas. Su función no es decir para que el estudiante se dedique a oir, su rol no es explicar para que el estudiante logre entender, tampoco debe dedicarse a demostrar mientras sus estudiantes se dedican a experimentar. Su función es mediar para que el estudiante se pueda emancipar. El rol del profesor es configurar ambientes de aprendizaje en los que sus estudiantes tengan auténticas oportunidades para comprender el sentido de lo que aprenden y configurar los significados a su propio ritmo, mediante las vivencias y experiencias individuales y colectivas, orales y escritas.

El profesor no debe fungir como un simple explicador de sus saberes, no debe ser un simple transmisor de conocimientos acabados que él posee, elaborados por otras personas, debe orientar a sus estudiantes para que ellos configuren su propio conocimiento mediante la estimulación y potenciación de su pensamiento crítico, reflexivo y creativo, para lo cual es necesario el diálogo en clase, la conversación amena y agradable. En este sentido, el profesor es un estimulador y no un instructor. Así el estudiante se sentirá reconocido y asumirá un papel activo y protagónico, con el fin de realizar un aprendizaje comprensivo y emancipatorio que le permita una aplicación real de los conocimientos. A esta actitud del profesor en el ámbito pedagógico se le denomina maestro facilitador o mediador.

El profesor tiene responsabilidad en el proceso de formación, pero también el estudiante es responsable de su proceso de aprendizaje. El profesor es protagonista en tanto diseña el microcurrículo, pero esta configuración curricular debe ser el resultado de tener en cuenta de manera holística la personalidad de sus estudiantes. "Es un agente de cambio que participa desde sus saberes, en el enriquecimiento de los conocimientos y valores más preciados de la cultura y la sociedad" (Addine et al., 2004, p. 11). El profesor no debe ser autoritario, pero sí debe mostrar una autoridad como profesional de la educación, basada en el dominio de la episteme de su disciplina, el conocimiento de la didáctica de la misma y la comprensión humanista del ser humano y la dinámica grupal. Asume la orientación creadora del proceso de enseñanza-aprendizaje, "planificando y organizando la situación de 
aprendizaje, orientando a los alumnos y evaluando el proceso y el resultado" (Addine et al. 2004, p. 11).

Indudablemente, al igual que no existen dos estudiantes que aprendan de la misma manera, tampoco existen dos profesores que profesen lo mismo, no existen dos profesores que enseñen de la misma manera, incluso aunque desarrollen la misma asignatura en una misma escuela y en un mismo nivel educativo. Tampoco el profesor profesa lo mismo a grupos de estudiantes diferentes, aunque él enseñe la misma asignatura en el mismo grado escolar y a grupos diferentes. En este caso, sus estrategias de enseñanza difieren en cada grupo, su estilo de enseñar en cada grupo escolar es diferente, porque sus métodos de enseñanza se configuran con los estilos, estrategias y métodos de aprendizaje de sus estudiantes.

En una escuela hispana de Harlem, el poeta Kenneth Koch (1970, 1977) incitó a niños y niñas de cuarto y quinto grado a crear poesías creativas. Lo mismo hizo con ancianos solitarios y enfermos. Los resultados fueron impresionantes. El aprendizaje activo, participativo, productivo y creativo requiere de un profesor también creativo que cautive a sus estudiantes, los atraiga y seduzca con su pasión por enseñar, al relacionar los contenidos con la experiencia vital de estos. El profesor debe respetar a sus estudiantes, comprenderlos y darles seguridad para que ellos puedan expresar con sosiego lo que sienten y piensan. El docente debe esperar con paciencia el resultado del aprendizaje de sus estudiantes. Él sabe que ellos pueden, deben y van a aprender. Y ellos también lo saben. Ahora bien, no existe un método omnipotente para educar y enseñar a los estudiantes. Todos los métodos son iguales. Un profesor puede ser exitoso y querido por sus estudiantes aun utilizando conferencias y clases magistrales, y puede ser rechazado por sus estudiantes a pesar de que utilice métodos activos y participativos. El método es el profesor. Tampoco existen contenidos bonitos y contenidos feos, contenidos fáciles y contenidos difíciles. Todos los contenidos son iguales. Para que el estudiante tenga un aprendizaje productivo, creativo y profundo, debe enamorarse de la asignatura, para lo cual debe tener un intercambio afectivo con el contenido de esta. Pero los contenidos son asépticos y no tienen afectos. Solo el profesor tiene afectividad. El profesor debe entonces transferir sus afectos al contenido de la asignatura, con el fin de que el estudiante se enamore de la asignatura a través del intercambio afectivo con el docente. Aprender y enseñar no es más que comunicarse afectivamente. 
No existe tampoco una receta sobre el rol a desarrollar para ser un profesor ejemplar y excelente, pero hay una condición insoslayable para el éxito pedagógico: al profesor debe gustarle la profesión de educar, debe ser apasionado y debe amar la actividad de la educación. Si al profesor no le gusta el arte de enseñar pues muy difícilmente podrá contagiar a sus estudiantes y orientar su motivación hacia el aprendizaje. Un profesor de excelencia se preocupa por sus estudiantes y por su actividad mental, estimula su pensamiento y se concentra más en ellos que en la asignatura que desarrolla, para de esta manera "desafiar a sus alumnos desde la más tierna y adecuada edad a través de juegos, de historias, de lecturas para comprender la necesidad de la coherencia entre el discurso y la práctica" (Freire, 2012, p. 42). El estudiante es el fin, no la asignatura, y el contenido es el medio para alcanzar el fin: la estimulación de los procesos cognitivos de los estudiantes.

La máxima de que un docente enseña a niños, y no materias, no es una subestimación de la materia sino una manera de decir que si uno no entiende de dónde vienen los niños en el contexto del aula, es muy posible que estos no lleguen a captar el significado, la significación y la utilidad previstas de esa materia. (Sarason, 2002, p. 75.)

Por otro lado, la escuela debe ser una institución cultural abierta a la comunidad y a la sociedad. Los profesores deben establecer buenas relaciones con los padres de familia, quienes tienen conocimientos y constituyen un baluarte importante para la formación de los estudiantes. De hecho, conocen más a sus hijos de lo que podrían conocerlos los profesores. "Los padres no son intrusos, sino parte de la empresa educativa. Pueden ser valiosos recursos, si no se los ve como «meros» padres" (Sarason, 2002, p. 73).

El rol del profesor en el siglo XXI no está relacionado con la transmisión de conocimientos, es necesario enseñar a pensar y también pensar para enseñar. Pensar es el método, por lo tanto, no hay que enseñar ningún método para pensar (Dewey, 1964). Cuando el profesor incita al estudiante para que piense, el contenido de la asignatura muestra su fragilidad, se desmoronan las recetas y los estudiantes se convencen de que no existe una verdad absoluta. Esto, sin lugar a dudas, garantiza que ellos puedan enfrentarse a los cambios siempre 
constantes de la sociedad. Ahora bien, pensar no solo es una actividad intelectual o cognoscitiva, pensar implica problematizar la realidad, no solo contemplarla, por eso el pensamiento tiene que ser crítico, creativo y reflexivo. Tanto el estudiante como el profesor deben ser pensadores que propongan soluciones a los diversos problemas que enfrentan. Se piensa para actuar no solo para conocer, lo cual exige investigar.

No hay investigación sin enseñanza ni enseñanza sin investigación (Freire, 2014). La investigación, la búsqueda, la indagación son procesos inmanentes al acto de enseñar, son cualidades inherentes al rol del profesor, quien busca, indaga e investiga para poder enseñar. Por eso hablar de profesor investigador es una tautología, porque la investigación es condición de la enseñanza, todo profesor es investigador, es redundante hablar del profesor investigador, lo que se necesita es que los profesores en nuestra praxis pedagógica cotidiana nos asumamos como investigadores por el mismo hecho de ser profesores.

Los profesores somos políticos, hacemos política al hacer educación. Y si soñamos con la democracia debemos luchar día y noche por una escuela en la que hablemos a los educandos y con los educandos, para que escuchándolos podamos también ser oídos por ellos. (Freire, 2012, p. 114)

Los estudiantes nos pueden enseñar mucho, no solo ellos aprenden de nosotros, sino que el profesor también aprende mucho de sus estudiantes. El docente que se niega a aprender junto a sus alumnos rompe la unidad dialéctica entre enseñar y aprender y se convierte en un ser elitista (Freire, 2013). El propio educador necesita ser educado, y ¿qué mejor educador para los profesores que sus propios estudiantes?

Los estudiantes tienen un saber muy valioso que los profesores deberíamos asumir. Nosotros no lo sabemos todo y tampoco lo ignoramos todo. Los estudiantes tampoco. Todos los seres humanos sabemos algo y todos ignoramos algo, por eso siempre estamos aprendiendo entre todos. La idea de que el profesor sabe y por eso enseña al estudiante que no sabe, es una idea autoritaria y excluyente que considera al estudiante un objeto. Tanto el profesor como los estudiantes son sujetos de la educación. Ambos educan y son educados mutuamente. El conocimiento no es un dato, inmóvil, concluido, terminado, para ser transferido por quien lo adquirió a quien supuestamente todavía no lo posee (Freire, 2013). 
Los profesores "son los órganos mediante los cuales los alumnos son puestos en relación efectiva con las materias" (Dewey, 2003, p. 66). Son agentes mediadores entre el conocimiento y los estudiantes, estimulan el desarrollo de sus habilidades y destrezas, y fortalecen las actitudes y valores de estos. El profesor no debe ser un dictador de clases, no debe ser un impartidor de asignaturas, su rol no es transferir a los estudiantes los conocimientos que él ya se sabe. La asignatura no es un fin en sí misma, es un medio curricular para cumplir una intencionalidad formativa. Es una herramienta educativa, es un pretexto para formar.

El verdadero profesor devela las potencialidades de sus estudiantes, se concentra más en las virtudes y cualidades positivas que en sus defectos y fallas. El verdadero profesor contribuye a la emancipación de sus estudiantes, es su liberador. Dewey (2004) consideraba que la acción creativa de los científicos es muy importante para la transformación del mundo, y que las escuelas deberían privilegiar el pensamiento concreto, no el pensamiento abstracto. Pensaba que el profesor es responsable de las acciones futuras de los estudiantes, porque lo que el niño haga en el futuro depende de lo que reciba en el presente, y el profesor es responsable de las ideas que los estudiantes configuran en el presente vivido, a partir de lo que hace en su cotidianidad. Giroux (1997) le asigna al profesor un rol de intelectual transformativo que debe combinar la práctica pedagógica con la reflexión crítica y creativa, para lo cual es necesario lograr procesos de integración entre la política y la pedagogía, con una concepción liberadora; es decir, "servirse de formas de pedagogía que traten a los estudiantes como sujetos críticos, hacer problemático el conocimiento, recurrir al diálogo crítico y afirmativo, y apoyar la lucha por un mundo cualitativamente mejor para todas las personas" (p. 178).

El profesor del siglo XXI infunde confianza en sus estudiantes, transmite entusiasmo y deseo de aprender, es una persona bien preparada, un líder, pero su atención y concentración no se dirige hacia la asignatura sino hacia el estudiante, para lo cual utiliza la pregunta problematizadora como mecanismo de activación de la atención, concentración y motivación de los estudiantes. El profesor del tercer milenio estimula el pensamiento, y no trasmite información ni conocimiento, no da respuestas, hace preguntas. Su estilo es socrático. Rogers (1973) define el papel del formador como el de un facilitador del aprendizaje. El elemento básico al desempeñar este rol es la relación personal 
entre el profesor y el estudiante. La actitud del facilitador debe tener algunas cualidades, tales como: mostrar lo real o lo genuino, el interés solícito, la confianza, el respeto no posesivo, el entendimiento empático y la capacidad de escuchar con sensibilidad.

La principal tarea del profesor del siglo XXI es entusiasmar al estudiante por el proceso de aprendizaje, estimular el deseo de aprender, crear el enigma (Meirieu, 2001, 2009). El profesor no debe darles a los estudiantes los conocimientos ya fabricados y hechos como si fuesen una cosa o un producto terminado, debe enseñarlos a descubrir el conocimiento que él mismo ya se sabe, e incluso debe incitarlos a que transiten por caminos intelectuales desconocidos también para él.

Meirieu (2009) habla de "promover un enigma con el saber: promover un saber con el enigma", es decir, presentar a los estudiantes una situación problémica que estimule su curiosidad e incite su capacidad de asombro. Esto conlleva a que el estudiante aprenda con una mayor profundidad dado su alto grado de motivación. El enigma provoca mayor deseo de aprender, y mientras más aprende, más enigmas aparecen, formando una configuración enigma-saber, en el que ambos constituyen componentes de un mismo proceso de aprendizaje. "Un juego siempre inacabado, en la medida en que cuanto más sabemos más deseamos saber, y en que la solución, en contra de lo esperado, siempre hace crecer el enigma" (p. 109).

Otras dos tareas urgentes y emergentes del profesor del siglo XXI son configurar y problematizar. El rol del profesor se cumple desde la configuración, al establecer relaciones, entrelazamientos e interconexiones, que toman al ser humano como centro, al develar su condición bio-psico-social, y usándolo como puente para la enseñanza de las diversas asignaturas. La condición biogenética, neuropsicológica y sociocultural del ser humano deben convertirse en ejes articuladores de las estrategias pedagógicas utilizadas por los profesores en su desempeño.

Simmel (2008) propone tres tareas para la actividad del profesor: aportar un saber, cultivar el ser y enseñar a hacer, la cual genera una tensión entre las dos anteriores. No se trata de potenciar solo la dimensión cognoscitiva o la dimensión axiológica del estudiante, sino de combinar ambas con la capacidad de hacer como centro y eje articulador. Esta capacidad no es ni un saber ni un ser, sino un ser formado por el saber orientado hacia la capacidad de hacer. De esta manera, el rol del profesor es práctico y vitalista. Es práctico porque se concreta 
en la actividad de enseñanza, en la clase; y es vitalista porque concibe su accionar formativo como vida, en constante movimiento y dinámica mientras haya existencia humana.

El profesor debe ser humilde para sentirse a la altura de sus estudiantes y a la vez elevarse en un vuelo intelectual inalcanzable que estimule en ellos el deseo de volar para alcanzarlo. "Esta es la paradoja de la relación educativa; requiere que el educador sea percibido al mismo tiempo como alguien muy cercano y muy lejano" (Meirieu, 2009, p. 111). Debe estar cerca de sus estudiantes para que ellos logren algún día imitarlo y actuar como él, pero también debe estar lejos de ellos para mantener vivo el deseo de alcanzarlo. Además de conocer las particularidades psicológicas individuales de sus estudiantes, el profesor deberá también aprender a conocerse a sí mismo y dominar sus conflictos personales antes de desarrollar su labor formativa. De lo contrario, sus estudiantes se convertirán en un insumo para descargar en ellos sus propios conflictos inconscientes irresueltos (Freud, 2011).

Se podrá cambiar los currícula, reducir el tamaño de las clases, recurrir a la programación en bloques y muchas cosas más, pero a menos que los docentes estén mejor preparados para crear y mantener contextos de aprendizaje productivo, los cambios buscados no se producirán. (Sarason, 2002, p. 234.)

Varios autores humanistas han propuesto los rasgos que debe poseer el profesor para cumplir con semejante cometido. En este tipo de educación humanista el profesor se caracteriza por tener una relación de respeto y admiración hacia sus estudiantes. Rogers (1978) considera que el profesor debe asumir una actitud de no directividad, no debe poner restricciones curriculares a los estudiantes ni limitarlos en cuanto a su relación con el contenido de la asignatura, sino que debe proporcionarles todos los recursos necesarios para su aprendizaje. Desde esta mirada, se rechazan las posturas egocéntricas y autoritarias de aquellos profesores que quieren imponer su criterio a los estudiantes, dominarlos, controlarlos y dirigirlos por un camino trazado por él.

El profesor debe ser auténtico y genuino ante sus estudiantes, debe sensibilizarse con sus problemas, necesidades, sentimientos, emociones y percepciones; debe ponerse en su lugar, tener empatía hacia ellos, comprenderlos, no pretender cambiarlos y aceptarlos como son, 
mostrando hacia ellos una actitud comprensiva (Good y Brophy, 1996). Es importante que el profesor no sea rígido ni dogmático, que asuma una actitud flexible y un pensamiento reflexivo y creativo, que esté abierto ante nuevas formas de enseñanza y tenga en cuenta diversas opciones educativas, fomentando el espíritu cooperativo de sus estudiantes (Sebastián, 1986).

El rol del profesor es científico, pero también es artístico y sobre todo ético. De nada sirve la aplicación de las ciencias de la educación en nuestra práctica pedagógica si no somos éticos y si no desarrollamos nuestra actividad con amor, pasión y con arte. Educar implica integrar las ciencias con la ternura. Cela y Palou (2011) enumeran tres acciones muy concretas que deben ejecutar todos los profesores al comenzar cada día su actividad formativa: "mirar que los niños lleven el desayuno y la ropa necesaria cuando lleguen a la escuela, intuir si necesitan un beso en la mejilla y despertar su interés hacia las cosas de nuestro mundo" (p. 26). Los docentes debemos amar a nuestros estudiantes y demostrarles cariño, comprensión, reconocimiento y consideración, lo que estimula su autoestima y potencia sus capacidades. Nunca debemos mentir a nuestros estudiantes y mucho menos dañar su imagen o hablar mal de ellos. Si lo que queremos expresar de ellos es algo negativo que realza sus defectos y errores, entonces es mejor callar, y hablar solamente para elogiarlos y resaltar sus virtudes y aciertos. A veces el silencio es muy elocuente. Educar es una actividad que requiere una alta vocación, esta es una de las profesiones más nobles y humanas que existen, educar es un acto de amor y recepción humana, un acto de aceptación sin condiciones, de reconocimiento del valor del otro. El profesor exitoso debe amar esta profesión, actuar con alegría y felicidad, y sentirse atraído por la novedad que representa cada estudiante con el que interactúa, vibrar ante ellos, escucharlos, respetarlos, acompañarlos en sus vicisitudes y éxitos, y entusiasmarlos por aprender cada día más.

Poeydomenge (1986) señala la importancia de crear un clima de confianza en el aula, para lo cual es de un alto valor poner sus conocimientos, experiencia y tiempo, a disposición de sus estudiantes, haciéndoles saber que pueden contar con su colaboración incondicional y ayuda desinteresada en cualquier momento que lo necesiten. En su desempeño pedagógico el profesor debe fomentar la creatividad de sus estudiantes, su originalidad y el autoaprendizaje, debe lograr la autodirección de estos e interesarse por ellos como seres humanos holísticos, 
partir siempre de sus necesidades individuales y de sus potencialidades para enfrentarlas, de esta manera crea y fomenta un clima social básico para garantizar el éxito de la comunicación de la información académica y emocional (Hamachek, 1987). El profesor es un mediador entre el saber sociocultural y los procesos de apropiación de los estudiantes (Medina 1996), y un facilitador de la capacidad potencial de su autorrealización, debe potenciar no solo su aprendizaje sino su desarrollo, autonomía y autoconfiguración.

El profesor debe ser entendido como un agente cultural que enseña en un contexto de prácticas y medios socioculturalmente determinados (Hernández, 2014), de esta manera debe promover espacios configurativos de aprendizaje, zonas de construcción (Newman et al., 1991) que permitan la apropiación individual de conocimientos, pero estimulada por sus ayudas didácticas y aportes en las actividades y situaciones de aprendizaje diseñadas intencionalmente, con una finalidad formativa. Hernández (2014) señala que el profesor debe crear y construir juntamente con sus estudiantes zonas de desarrollo próximo, a partir de estructurar sistemas de andamiaje estratégicos y flexibles. Es cierto que el docente no determina el aprendizaje del estudiante, pero sí influye, provoca, perturba, estimula y potencia, en el sentido de que el aprendizaje es un proceso interactivo, es una configuración tríadica: estudiante-contexto-profesor.

Finalmente, es preciso significar que la educación debe promover el desarrollo de la capacidad crítica en los estudiantes con el fin de que este tenga la posibilidad de optar, decidir y elegir libremente, y en este sentido, el rol del profesor debe caracterizarse por el aporte de opciones, sin límites establecidos, desde la pluralidad, la libertad y la confianza. El profesor del tercer milenio estimula el deseo y el entusiasmo por aprender, se preocupa por estos, más que por los propios contenidos de la asignatura que desarrolla. Estos son importantes, pero no basta con ellos. El profesor tiene que develar el potencial axiológico y formativo que tienen los contenidos de las asignaturas, para despertar y estimular en sus estudiantes el deseo de aprender incluso fuera del aula de clases. El proceso formativo del estudiante debe extenderse hasta el hogar.

\section{Dime cómo evalúas y te diré cómo enseñas}

Stufflebeam y Shinkfield (1995) señalan que la evaluación sistemática emerge en la década de los treinta, por cuanto en esos años 
no existía un movimiento reconocible, a pesar de que no era desconocida. Su sistematización comienza con Tyler (1986), aunque antes se encuentran referencias y experiencias evaluativas aisladas y específicas de determinadas disciplinas, como por ejemplo en la psicología el uso de test psicométricos, que fueron el cimiento de las pruebas objetivas y de escala. Colás (2000) destaca que en esta época la evaluación es relacionada con la medición, a partir de la influencia que ejerció en la educación el desarrollo de los test y de la estadística. Hoy sabemos que evaluar no es medir. La medición solo aporta datos e informaciones, y la evaluación aporta comprensiones, argumentos, interpretaciones y valoraciones. Cuando hacemos un examen no estamos evaluando, estamos midiendo. Evaluar es analizar el proceso de aprendizaje que lleva a cabo el estudiante, interpretar y emitir juicios de valor sobre dicho proceso, que incluyen los resultados del examen.

No sabemos, ni sabremos nunca, cómo medir el grado de conocimientos o de comprensión de otra persona. Y está claro que no podremos hacerlo formulándole preguntas. Todo lo que llegamos a averiguar es lo que no sabe, que es en cualquier caso para lo que sirven nuestras pruebas y "tests", que funcionan como trampas en las que deben caer los estudiantes. (Holt, 1982, p. 37.)

La evaluación es considerada por Álvarez de Zayas (1997) como un proceso inherente a la educación, "que se inserta en el ambiente general de la sociedad, es de naturaleza totalizadora, remitido a la complejidad de los factores que intervienen en el proceso educativo, en el que juega papel fundamental el profesor, guía de dicho proceso" (p. 78).

La evaluación es un proceso socialmente necesario, es inmanente a la sociedad e inherente al ser humano, quien realiza su valoración al reflejar en su conciencia el sentido y significado que tienen para él los objetos, fenómenos, procesos y personas con las que interactúa. De ahí que la evaluación sea considerada como un proceso de legitimación cultural, que se ha configurado como un mecanismo de justificación en sí mismo del progreso social.

Evaluar es formular juicios de valor acerca de un fenómeno conocido, el cual vamos a comparar con unos criterios que hemos establecido de acuerdo con unos fines que nos hemos trazado. 
Por ello en toda evaluación se requiere determinar los fines e intenciones que buscamos, delimitar los criterios que usaremos al establecer las comparaciones y recoger la información para garantizar que el juicio emitido corresponda a la realidad. (De Zubiría, 2011, p. 61.)

Evaluar es valorar, significa asignarle valor a algo, no quitarle valor. Cuando evaluamos, debemos darle valor al proceso de aprendizaje de los estudiantes, concentrarnos en sus avances, en sus logros, no en sus desaciertos y errores, aunque estos van a aparecer y tienen un valor didáctico extraordinario, pero la finalidad de la evaluación no es buscar las fallas de los estudiantes sino sus tinos, lo cual nos permitirá interpretar su proceso. Evaluamos para comprender.

Toda evaluación es un diagnóstico que permite toma de decisiones en correspondencia con los resultados del mismo. Ahora bien, la comprobación de los resultados del proceso de aprendizaje permite evaluar si hemos alcanzado los objetivos que nos hemos propuesto, todos, profesores y estudiantes, y no solo los estudiantes. A veces se piensa que la evaluación solo cuestiona el desempeño de los estudiantes, pero este proceso debe preguntarse también por el rol de los docentes. La evaluación no debe hacerse solo al final del proceso, incluso no es un momento concreto del proceso educativo, no es un acto específico, sino un elemento inmanente a todo el proceso. Vega (2004) refiere que durante mucho tiempo se ha considerado a la evaluación solo como el medio a través del cual la institución educativa, en general, y el profesor, en particular, ejercen su función de poder, control y dominio sobre los estudiantes, al calificarlos y decidir el rumbo posterior que tomará este en lo relacionado con su vida escolar. Lamentablemente, este criterio tan estrecho y limitado acerca de la evaluación incide no solo sobre el futuro escolar del estudiante, sino que, en muchas ocasiones, puede llegar a decidir el rumbo total de la vida de un ser humano. Casi siempre evaluamos a la persona del estudiante y no su desempeño, evaluamos para castigar y no para mejorar el desempeño de los sujetos. Debemos evaluar para que los estudiantes aprendan. La evaluación debe ser formativa.

Comprendiendo al ser humano como un ser que ama, piensa y actúa (Wallon, 1984, 1987), el proceso de evaluación no debe desarrollarse al margen de las dimensiones valorativa, cognoscitiva y praxeológica, es por ello que proponemos que se enfoque en las tres configuraciones 
que caracterizan la formación y el desarrollo humano integral: la afectiva-emocional, la cognitiva-intelectual y la instrumental; por tanto, pudiéramos referirnos a tres tipos de evaluación: axiológica, cognoscitiva y procedimental, es decir, la evaluación del ser, el saber y el hacer cotidiano de los estudiantes. Por ejemplo, es antipedagógico que el profesor haga una evaluación en la que expresa la primera mitad de una oración y solicita al estudiante que culmine la frase, como respuesta a la primera parte de la oración. Toda evaluación, y toda pregunta, que formule el profesor deben estimular el pensamiento del estudiante. Las respuestas de los estudiantes deben ser el resultado de una estimulación cognitiva e intelectual, deben ser consecuencia de su autodeterminación y de su esfuerzo mental. La pregunta debe ser una interpelación por parte del profesor y "en los trabajos de evaluación se trata de qué sabe el alumno; y apenas en segunda instancia, de lo que él no sabe" (Simmel, 2008, p. 104).

En ocasiones, el proceso de evaluación sobre el aprendizaje realizado por parte de los estudiantes tiene mejores resultados cuando se aplica sustentado en la observación por parte de los profesores de los comportamientos individuales y sociales relevantes de los estudiantes y no se efectúan exámenes, ni se asignan calificaciones cuantitativas (Dewey, 2004). La pedagogía del siglo XXI promueve una evaluación democrática, dialógica y participativa. La configuración de sentido y significado en los procesos de aprendizaje implica la promoción de relaciones más democráticas en el aula. De esta manera, la calificación [que no es lo mismo que evaluación] debe ser cada vez más participativa. Los estudiantes deben participar en el diseño y desarrollo del proceso evaluativo, para que configuren la idea de que el aprendizaje es ante todo un fenómeno compartido (Herrera, 2013). Esta evaluación dialogada [la coevaluación] debe combinarse con la heteroevaluación, actos que amortiguan el impacto de la evaluación tradicional, asociada al autoritarismo del profesor.

Tradicionalmente los autores se han referido a dos tipos de evaluación: la sumativa y la formativa. La sumativa permite valorar si los alumnos promueven o no al siguiente nivel educativo. La evaluación formativa le permite al docente introducir modificaciones en las estrategias didácticas. La evaluación en este tercer milenio debe ser formativa y promover el aprendizaje de los estudiantes. No solo debe analizarse como un momento final para el control de lo aprendido, sino como un momento inicial y permanente que estimula e incita el deseo de aprender. 
Para que la evaluación sea formativa y promueva el aprendizaje, los profesores no pueden tomarla como un mecanismo de dominación y control. Los docentes deben partir de una actitud abierta (Farjat, 1998). El estudiante debe percibir que el profesor es transparente y que no está utilizando la evaluación para sancionarlos. De esta manera, el alumno asumirá una actitud positiva hacia esta. En definitiva, lo más importante no es la nota o calificación sino el aprendizaje. Si el profesor utiliza la evaluación como un mecanismo amenazador, entonces el estudiante le hará rechazo a la misma y la considerará como su principal verdugo.

Basándonos en la teoría de los intereses cognoscitivos de Habermas (1982), podemos identificar tres tipos de evaluación: explicativa, comprensiva y crítica. La explicativa es una acción instrumental de carácter cuantitativo, con énfasis técnico y administrativo. La evaluación comprensiva tiene un carácter cualitativo, cultural, histórico, social y comunicativo, y la crítica es emancipatoria, se encamina a la mejora, al cambio y a la transformación. Santos (1993) considera que la evaluación es un proceso de diálogo, comprensión y mejora. En cambio, la evaluación como acción técnica instrumental expresa una visión de racionalidad técnico-administrativa que tiene una mirada restringida, burocrática, autocrática y falsamente neutral (Riveros, 1999).

En ocasiones, se habla de evaluación del resultado y evaluación de proceso. También se habla de una evaluación integral u holística. La práctica evaluativa tradicional es restringida, se concentra en el resultado y soslaya el proceso, fragmenta los contenidos e incluso al sujeto. Es necesaria una evaluación más global, integradora y holística, que reconozca el carácter integrador, sinérgico y totalizante del proceso pedagógico.

La evaluación integral por procesos es aquélla que busca una valoración cualitativa, permanente, integral, sistemática y una construcción apreciativa y formativa, subjetiva e intersubjetiva; analizando la práctica educativa del estudiante en su totalidad y en la dinámica misma de su proceso. (Estévez, 1997, p. 45.)

La evaluación integral por procesos es holística por cuanto tiene en cuenta la totalidad del proceso e intenta analizarlo, comprenderlo y armonizarlo en sus subprocesos, momentos y eventos dinámicos interactivos.

La práctica evaluativa de los profesores está más relacionada con sus creencias que con las acciones concertadas que respondan a 
qué, por qué, para qué, cómo, cuándo, dónde y quién evalúa, de ahí que no responda a los principios de la formación (Escorcia, Figueroa y Gutiérrez, 2008). En ocasiones, en las instituciones educativas se utilizan indicadores de logro o de desempeño para formular o evaluar las competencias de los estudiantes. El indicador es un "comportamiento observable a partir del cual podemos inferir el alcance de un objetivo o el dominio de una capacidad" (Meirieu, 2009, p. 220), por eso decimos que la competencia es interna y a la vez es externa. Es interna en tanto capacidad o configuración neuropsicológica (y en este sentido no se puede observar), y es externa porque se expresa en el desempeño humano, que es el plano donde podemos observarla y afirmar que el estudiante es competente. Sin embargo, no es posible deducir los indicadores a partir de la capacidad del estudiante o del objetivo formulado y estos no pueden expresarse en términos de una suma de indicadores que permitirían inferir su existencia (Meirieu, 2009), es por ello que la formulación de indicadores de desempeño siempre es una actividad artística de diseño, una acción subjetiva del profesor, de ahí que el acto de "elección de los indicadores y su pertinencia son siempre cuestionables" (Meirieu, 2009, p. 221). Sin lugar a duda, es una formulación didáctica y aproximativa, nunca será exacta, es un modelo operativo y microcurricular que diseña el profesor para lograr un acercamiento al desempeño del estudiante. Esta modelación no es la realidad educativa, el mapa no es el territorio.

Es muy difícil desarrollar procesos evaluativos que utilizan criterios externos definidos solo por el profesor. Desde esta mirada, la autoevaluación se convierte en una opción válida para darles participación a los estudiantes en el proceso formativo. Son ellos quienes deben expresar cómo se sienten en el proceso, qué tanto han avanzado, qué dificultades tienen para aprender y qué modificaciones sugieren a las actividades de formación propuestas por el profesor, "no tendría sentido defender un aprendizaje autoiniciado, autodirigido, autodeterminado si, al mismo tiempo, no se defendería la autoevaluación y la autocrítica respecto a él" (Palacios, 1978, p. 223).

Por otro lado, cada vez somos más los educadores e investigadores convencidos que reconocemos el hecho de que los exámenes convencionales y tradicionales de selección múltiple con única o múltiples respuestas no son útiles para la enseñanza ni para comprobar el grado de aprendizaje de los estudiantes. "Tales pruebas y exámenes 
conducen a maestros y alumnos a un estilo mecánico de educación, que si bien sirve para memorizar los conocimientos, es inoperante para desarrollar la comprensión o usar activamente lo aprendido" (Perkins, 2003, p. 27). Si esto es así y estamos convencidos de ello, ¿por qué entonces los seguimos utilizando?

Nussbaum (2013) cita a Obama, quien afirma que se deben elaborar exámenes que sirvan para evaluar si los estudiantes "poseen la aptitudes necesarias para el siglo XXI, como la resolución de problemas, el pensamiento crítico, la capacidad de iniciativa y la creatividad" (p. 182), porque las pruebas de selección múltiple con única respuesta y las pruebas de selección múltiple con múltiples respuestas no permiten evaluar las capacidades que requiere este tercer milenio: imaginación narrativa, pensamiento crítico y ciudadanía universal. Este tipo de prueba estandarizada tampoco permite valorar la verdadera capacidad y talento de los estudiantes por cuanto a todos se les pregunta lo mismo. Albert Einstein solía decir que todos los seres humanos somos genios, pero si juzgamos a un pez por su habilidad de trepar a un árbol, pasará el resto de su vida creyendo que es un idiota. La evaluación debe tener un enfoque personológico.

El estudiante no debe prepararse para un examen sino para la vida. Las actividades evaluativas deben enriquecer el intelecto y la afectividad humana, y establecer una relación entre la vida escolar y la vida cotidiana (Nussbaum, 2013), y para ello no se debe evaluar de manera cuantitativa sino cualitativa y descriptiva, una evaluación que oriente su proceso de aprendizaje y no solo esté encaminada a ofrecer una nota. Evaluar no es calificar, es valorar, es comprender. La evaluación es un proceso hermenéutico e intersubjetivo en el que tanto el profesor como el estudiante se esfuerzan en comprender al otro.

La evaluación por notas, que especula sobre el orgullo, no permite surgir, a propósito, este momento gozoso de toda creación. Ésta construye entre sujeto y objeto el puente del egoísmo, pone al alumno desde ese instante en una oposición artificial hacia el objeto. En lugar del verdadero interés, uno cuida uno artificial, el orgullo. Con ello se desplaza el punto ético central fuera de la obra. El juicio extraño es lo más importante para el alumno. Él trabaja por él. La evaluación por notas lo posiciona como competidor en la línea de sus camaradas. Su impulso de honor observa 
con envidiosa mirada, continuamente, a éste o aquel compañero, frente al cual debe mejorar, o de manera arrogante al que ha superado. (Simmel, 2008, p. 172)

Si los estudiantes se preparan para los exámenes solo porque quieren sacar buenas notas o ser los mejores del aula de clase, con seguridad no les irá tan bien como si estudiaran porque tienen interés. Si ellos se motivan por el aprendizaje y no solo por las calificaciones, resolverán problemas con más efectividad, analizarán mejor, razonarán con mayor habilidad mental y se plantearán cada vez más y mejores retos.

La evaluación tiene una intencionalidad formativa, su finalidad no es calificar. Lo importante no es qué nota se obtuvo o cuánto se sacó sino qué se logró y cuánto se aprendió (Estévez, 1997). El propósito de la evaluación no es identificar a los estudiantes que tuvieron éxito y a los que fracasaron, sino orientar su aprendizaje.

La mayoría de los profesores identifican y confunden evaluar con calificar, y reducen la evaluación a una cuantificación del saber. No es lo mismo evaluar que calificar. La evaluación está relacionada con el análisis y la interpretación de datos e información, y la calificación consiste en asignar números o letras al resultado del estudiante, catalogándolo de mejor o peor según una escala previamente establecida. Pero en realidad las calificaciones nos dicen muy poco del aprendizaje de los estudiantes. Evaluar es valorar y comprender. Calificar es excluir y cuestionar.

Las calificaciones no deben ser una forma de encasillar y clasificar a los estudiantes. Más bien constituyen una forma de comunicación con ellos. Las evidencias sobre su aprendizaje pueden obtenerse de un examen, pero también de un proyecto, de un ensayo o de una conversación. Aquí lo más importante es el aprendizaje y no la nota. Desde esta mirada, un profesor podría solicitar a sus estudiantes que se califiquen a sí mismos y que aporten evidencias y conclusiones sobre la profundidad y calidad de su aprendizaje.

Las altas calificaciones no develan necesariamente lo que sabe el estudiante o lo que podría hacer con lo que sabe. "Las buenas calificaciones no significan en absoluto que se haya comprendido algo. En la universidad se pide a menudo memorizar una gran cantidad de materia que no ejerce influencia alguna en las vidas futuras" (Bain, 2014, p. 24). Los estudiantes pueden obtener resultados en los exámenes sin 
necesidad de comprender el contenido de la asignatura y sin modificar la forma en que sienten, piensan y actúan.

El método de las calificaciones no siempre ha existido en la historia de la educación escolarizada. Quizá hace aproximadamente 200 años la sociedad le asignó a la escuela el encargo social de rendir cuenta de su gestión, y se les exigió a los profesores que "midieran" el aprendizaje de sus estudiantes. Hoy sabemos que el saber es inconmensurable. Ningún instrumento evaluativo puede determinar lo que sabe o no sabe un ser humano.

Las calificaciones jamás podrán predecir el éxito o el fracaso futuro de un estudiante. Por ejemplo, Martin Luther King obtuvo una calificación insuficiente en oratoria pública. Los estudiantes que sustentan su valor intelectual en las buenas calificaciones probablemente no aprendan al ritmo y profundidad que podrían hacerlo si se concentraran en su proceso de aprendizaje y no en las calificaciones.

\section{Conclusiones}

Como se aprecia, la enseñanza y la evaluación son procesos inseparables, entre ellas debe existir una coherencia profunda, permanente y estable, la forma como evaluamos influye más en la forma como los estudiantes aprenden que la forma como enseñamos (Escorcia, Figueroa y Gutiérrez, 2008). Es por ello que en las reflexiones que hacen los profesores para configurar el modelo pedagógico de la organización educativa deben tener en cuenta estas relaciones. Los análisis no deben ser aislados, deben tener en cuenta todas las configuraciones del proceso pedagógico. La forma en que evaluamos influye en el aprendizaje de los estudiantes y en la forma en que enseñamos. Dime cómo evalúas y te diré cómo enseñas.

En este proceso de diálogo académico entre los profesores y demás actores educativos es importante reflexionar sobre cómo enseñamos, cómo desarrollamos nuestras clases, esta es la esencia del proceso de configuración del modelo didáctico de la organización educativa, el núcleo central de la propuesta que nos permitirá definir las características de la clase en el modelo pedagógico asumido y el perfil del docente para implementar dicha propuesta. 


\section{Referencias}

Addine, F. et al. (2004). Didáctica. Teoría y práctica. Ciudad de la Habana: Pueblo y Educación.

Álvarez de Zayas, R. M. (1997). Hacia un currículum integral y contextualizado. La Habana: Academia.

Ausubel, D. (1958). Theory and problems of child development. New York: Grune Stratton.

Ausubel, D. (1963). The psychology of meaningful verbal learning. Stratton, New York: Grune Stratton.

Ausubel, D. (1980). Psicología educativa. Un punto de vista cognoscitivo. México: Trillas.

Bain, K. (2007). Lo que hacen los mejores profesores universitarios. España: Universidad de Valencia.

Bain, K. (2014). Lo que hacen los mejores estudiantes de universidad. España: Universidad de Valencia.

Ball, S. (1988). Staff during the teachers' industrial action: Context, conflict and proletarianisation. British Journal of Sociology of Education, 9(3), 38-57.

Bruner, J. (2000). La educación, puerta de la cultura. Madrid: Visor. Bruner, J. (2012). La importancia de la educación. Barcelona: Paidós.

Castorina, J. A. et al. (1996). Piaget-Vygotsky: contribuciones para replantear el debate. Buenos Aires: Paidós.

Cela, J. y Palou, J. (2011). Carta a los nuevos maestros. Barcelona: Espasa. Colás, M. (2000). Evaluación educativa: Panorama científico y nuevos retos. En T. González (Coord.), Evaluación y gestión de la calidad educativa. Un enfoque metodológico (pp. 38-55). Málaga: Aljibe.

Comenio, J. A. (2012). Didáctica magna. Madrid: Akal.

Contreras, J. (1999). Enseñanza, currículum y profesorado. Madrid: Akal.

De Zubiría, J. (2011). Los modelos pedagógicos. Hacia una pedagogía dialogante. Bogotá: Magisterio.

De Zubiría, M. (2008). Las teorías de Pedagogía Conceptual. Bogotá: Fundación Internacional de Pedagogía Conceptual.

Dewey, J. (1926). La escuela y el niño. Madrid: Ediciones de la Lectura. Dewey, J. (1964). La ciencia de la educación. Buenos Aires: Losada.

Dewey, J. (1989). Cómo pensamos. Barcelona: Paidós.

Dewey, J. (1997). Mi credo pedagógico. León: Universidad de León.

Dewey, J. (2003). Experiencia y educación. Madrid: Biblioteca Nueva. 
Dewey, J. (2004). Democracia y educación. Una introducción a la filosofia de la educación. Madrid: Morata.

Díaz-Barriga, A. (2012). Pensar la didáctica. Buenos Aires: Amorrortu.

Escorcia, R., Figueroa, R. y Gutiérrez, A. (2008). La evaluación de los aprendizajes en las instituciones de educación superior. Reto de la educación pública en Colombia. Santa Marta: Unimagdalena.

Estévez, C. (1997). Evaluación integral por procesos. Una experiencia construida desde y en el aula. Bogotá: Magisterio.

Ferrini, M. R. (coord.) (2001). Bases didácticas. México: Progreso.

Finkel, D. (2008). Dar la clase con la boca cerrada. España: Universidad de Valencia.

Flórez, R. (2005). Pedagogía del conocimiento. Bogotá: McGraw-Hill.

Freire, P. (2012). Pedagogía del oprimido. Madrid: Siglo XXI.

Freire, P. (2013). La importancia de leer y el proceso de liberación. México: Siglo XXI.

Freire, P. (2014). Pedagogía de la Autonomía. Saberes necesarios para la práctica educativa. México: Siglo XXI.

Freud, A. (2011). Introducción al psicoanálisis para educadores. México: Paidós.

Freud, S. (2012). El porvenir de una ilusión. México: Taurus.

Giroux, H. (1997). Los profesores como intelectuales. Barcelona: Paidós.

Good, T. L. y Brophy, J. E. (1996). Psicología educativa contemporánea. México: McGraw-Hill.

Habermas, J. (1982). Conocimiento e interés. Madrid: Taurus.

Hamachek, D. E. (1987). Humanistic Psychology. Theory, Postulates and Implications for Educational Processes. En J. A. Glover y R. R. Ronning (Eds.), Historical Foundations of Educational Psychology (pp. 48-67). New York: Plenum.

Heidegger, M. (1978). ¿Qué significa pensar? Buenos Aires: Nova.

Herbart, J. F. (1806). Pedagogía general derivada del fin de la educación. Madrid: Ediciones de la Lectura.

Hernández, G. (2014). Paradigmas en psicología de la educación. México: Paidós.

Hernández, S. (1969). Metodología general de la enseñanza. México: Unión Tipográfica.

Herrera, J. D. (2013). Pensar la educación, hacer investigación. Bogotá: Universidad de la Salle.

Holt, J. (1982). El fracaso de la escuela. Madrid: Alianza. 
Koch, K. (1970). Wishes, lies, and dreams: Teaching children to write poetry. Nueva York: Chelsea House.

Koch, K. (1977). I never told anybody: Teaching poetry writing in a nursing home. Nueva York: Random House.

Manuel, S. y Saavedra, R. (2001). Diccionario de pedagogía. México: Pax.

Marina, J. A. y Válgoma, M. de la (2014). La magia de leer. Barcelona: Penguin Random House.

Martínez, A. (2003). La enseñanza como posibilidad del pensamiento. En O. L. Zuluaga et al. (Eds.), Pedagogía y epistemología (pp. 83-109). Bogotá: Magisterio.

Maturana, H. (1999). Transformación en la convivencia. Santiago de Chile: Dolmen.

Medina, A. J. (1996). La dimensión sociocultural de la enseñanza. La herencia de Vygotsky. México: OEA. Instituto Latinoamericano de Comunicación Educativa.

Meirieu, Ph. (2001). La opción de educar: Ética y Pedagogía. Barcelona: Octaedro.

Meirieu, Ph. (2009). Aprender, sí. Pero ¿cómo? Barcelona: Octaedro.

Meirieu, Ph. (2011). Carta a un joven profesor. Por qué enseñar hoy. Barcelona: Grao.

Moreno, A. (1993). Aprendizaje y desarrollo operatorio. En J. I. Navaro (Ed.), Aprendizaje y memoria humana. Aspectos teóricos y evolutivos (pp. 48-70). Madrid: McGraw-Hill.

Morín, E. (2007). Articular los saberes. ¿Qué saberes enseñar en las escuelas? Buenos Aires: Universidad del Salvador.

Morín, E. (2008). La cabeza bien puesta. Repensar la reforma. Reformar el pensamiento. Buenos Aires: Nueva Visión.

Morín, E. (2011). La vía para el futuro de la humanidad. Barcelona: Paidós.

Morín, E., Ciurana, E. R. y Motta, R. D. (2003). Educar en la era planetaria. Barcelona: Gedisa.

Newman, D. et al. (1991). La zona de construcción del conocimiento. Madrid: Morata.

Nussbaum, M. (2013). Sin fines de lucro. Por qué la democracia necesita de las humanidades. Madrid: Katz.

Palacios, J. (1978). La cuestión escolar. Críticas y alternativas. Barcelona: Laía. 
Pasek, E. (2006). Reflexiones sobre la docencia: una práctica plena de intereses subyacentes. Educere,10(32), 31-45.

Perkins, D. (2003). La escuela inteligente. Del adiestramiento de la memoria a la educación de la mente. Barcelona: Gedisa.

Pestalozzi, J. E. (2011). Cómo Gertrudis enseña a sus hijos. México: Porrúa.

Piaget, J. (1945). El nacimiento de la inteligencia en el niño. Barcelona: Crítica.

Piaget, J. (1954). Inteligencia y afectividad. Buenos Aires: Aique.

Poeydomenge, M. L. (1986). La educación según Rogers. Propuestas de la no directividad. Madrid: Narcea.

Porlán, R. y Rivero, A. (1998). El conocimiento de los profesores. Sevilla: Diada.

Rancière, J. (2010). El maestro ignorante. Barcelona: Laertes.

Riveros, A. (1999). Evaluación de impacto. Bogotá: Gráficas América.

Rogers, C. (1973). ¿Liberté pour apprende? Paris: Dunod.

Rogers, C. (1978). Libertad y creatividad en la educación. Buenos Aires: Paidós.

Rousseau, J. J. (2011). Emilio o De la Educación. Madrid: Alianza.

Santos, M. A. (1993). La evaluación, un proceso de diálogo, comprensión y mejora. Archidona: Aljibe.

Santos, M. A. (2012). La escuela que aprende. Madrid: Morata.

Sarason, S. B. (2002). La enseñanza como arte de representación. Buenos Aires: Amorrortu.

Sebastián, J. (1986). Psicología humanista y educación. Anuario de Psicología, 34(1), 85-102.

Simmel, G. (2008). Pedagogía escolar. Barcelona: Gedisa.

Stufflebeam, D. y Shinkfield, A. (1995). Evaluación sistemática. Guía teórica y práctica. Barcelona: Paidós-MEC.

Titone, R. (1979). Metodología didáctica. Buenos Aires: Rialp.

Trejo, K. (2012). Metodología del proceso enseñanza-aprendizaje. México: Trillas.

Tyler, R. (1986). Principios básicos del currículo. Buenos Aires: Troquel. Vega, P. (2004). ¿Cómo evaluar instrumentos de conocimiento? En M. De Zubiría et al. (Eds.), Pedagogía Conceptual. Desarrollos filosóficos, pedagógicos y psicológicos (pp. 128-151). Bogotá: Fundación Internacional de Pedagogía Conceptual. 
Vygotsky, L. S. (1979). El desarrollo de los procesos psicológicos superiores. Barcelona: Crítica.

Vygotsky, L. S. (1981). Pensamiento y lenguaje. La Habana: Editorial Pueblo y Educación.

Wallon, H. (1984). La evolución psicológica del niño. Madrid: Grijalbo.

Wallon, H. (1987). Psicología y educación en el niño. Madrid: Ministerio de Educación y Cultura.

Watts, A. (2012). El camino del zen. Buenos Aires: Edhasa.

Zambrano, A. (2011). Didáctica, pedagogía y saber. Bogotá: Magisterio.

Zuluaga, O. L. (2003). El pasado presente de la pedagogía y la didáctica. En O. L. Zuluaga et al. (Eds.), Pedagogía y epistemología (pp. 56-77). Bogotá: Magisterio.

Zuluaga, O. L., Echeverri, A., Martínez, A., Restrepo, S. y Quiceno, H. (2003). Educación y Pedagogía: una diferencia necesaria. En O. L. Zuluaga et al. (Eds.), Pedagogía y epistemología (pp. 34-57). Bogotá: Magisterio. 
